\title{
Integrated approach for fracture characterization of hydraulically stimulated volume in tight gas reservoir
}

\author{
Belladonna Maulianda ${ }^{1} \cdot$ Aruvin Prakasan $^{1} \cdot$ Ron Chik-Kwong Wong ${ }^{2} \cdot$ David Eaton $^{3} \cdot$ lan Donald Gates ${ }^{4}$
}

Received: 30 January 2019 / Accepted: 9 April 2019 / Published online: 17 April 2019

(c) The Author(s) 2019

\begin{abstract}
Hydraulic fracturing is conducted on unconventional reservoir which has very low permeability. It increases the production from unconventional oil and gas reservoirs through the creation of a connected stimulated rock volume (SRV) with higher conductivity. The permeability and the SRVs dimension are important parameters which increase the performance of hydraulically fractured wells. Microseismic monitoring is used to estimate the seismically stimulated volume within the reservoir, which can provide a proxy for the SRV. Finite element analysis was used in this study in the determination of SRV characteristics by utilizing field data from a horizontal well hydraulic-fracturing program in the Hoadley Field, Alberta, Canada. Coupled fluid-flow geomechanics finite element (FE) model was used. The permeability of the SRV is altered to match the field bottom-hole pressure. The pressure drop and in situ stress changes within the SRV are determined through the matching of the FE model. Fracture aperture, number and spacing in the SRV are then inferred from the estimated reservoir parameters by using a semi-analytical approach.
\end{abstract}

Keywords Hydraulic fracturing $\cdot$ Stimulated rock volume $\cdot$ Unconventional reservoirs $\cdot$ Finite element method

Aruvin Prakasan

aruvinprakash@gmail.com

Belladonna Maulianda

belladona.wahyudi@utp.edu.my

Ron Chik-Kwong Wong

rckwong@ucalgary.ca

David Eaton

eaton@ucalgary.ca

Ian Donald Gates

idgates@ucalgary.ca

1 Department of Petroleum Engineering, Universiti Teknologi PETRONAS, 32610 Bandar Seri Iskandar, Perak Darul Ridzuan, Malaysia

2 Department of Civil Engineering, Schulich School of Engineering, University of Calgary, Calgary, AB T2N 1N4, Canada

3 Department of Geosciences, University of Calgary, Calgary, AB T2N 1N4, Canada

4 Department of Chemical and Petroleum Engineering, Schulich School of Engineering, University of Calgary, Calgary, AB T2N 1N4, Canada

\section{Introduction and literature review}

At present, in order for unconventional reservoirs in North America to be commercially productive, hydraulic fracturing is required. One of the standard procedures to produce these reservoirs is through multistage hydraulically fractured horizontal well (Wang 2015). A stimulated rock volume (SRV) is created after a tight gas reservoir is hydraulically fractured. The hydraulic fracture-natural fractures interaction (both open and reopened) within the SRV contributes to its high permeability and large drainage area (Guo et al. 2014). The SRV's dimensions and permeability are the important parameters that dictate the reservoir's recovery. Microseismic monitoring can provide insights into the SRV. Previous studies have linked the SRV to the microseismic cloud (Mayerhofer et al. 2010); however, there is an evidence that a simple correlation of the calibration of the seismically stimulated volume inferred from the microseismic cloud requires additional analysis (Cipolla and Wallace 2014). Moreover, the interactions of hydraulic and natural fractures require further understanding.

The permeability of a reservoir containing natural fracture was estimated by Oda (1986) through the SRV dimension and the cubic law. Rahman et al. (2002) suggest that 
the permeability of SRV was effected by fracture density, stimulation pressure and stresses within the reservoir. The authors created a model that considers shear slippage and the natural fractures propagation. An iterative method to obtain SRV permeability through the matching of computed SRV size with SRV determined from microseismic data was developed by Ge and Ghassemi (2011). The authors then used this permeability in determining pore pressure, stress distribution and the SRV. A semi-analytical equation was proposed by Bahrami et al. (2012). The equation models the fracture permeability taking into account the fracture spacing, fracture aperture and well-test permeability. Johri and Zoback (2013) proves that the slip of the natural fractures during hydraulic fracturing enhances the permeability of fracture. A coupled reservoir-geomechanics model was developed by Nassir (2013) to determine SRV permeability. The author found that at high injection rates, the maximum permeability enhancement occurs.

Some of the latest studies in hydraulic fracturing by using finite element analysis were conducted by Chen et al. (2017) where they created finite element model to investigate the interaction between hydraulic fracture and preexisting natural fracture. However, as the crack utilizes cohesive elements, the crack path needs to be predetermined. The fracture will only grow along and within predefined path. Gao and Ghassemi (2018) utilized finite element modeling to analyze hydraulic fracture propagation in layered rock. Similarly, they used cohesive element to define the crack which requires the pathway of the hydraulic fracture to be predetermined.

Despite considerable previous research undertaken to determine relationships among SRV permeability and dimensions, original rock permeability, natural fracture characteristics and the relationships in the context of geomechanical properties remain unclear. In this study, fluid injection and the changing of pressure is modeled by a three-dimensional (3D) finite element analysis (FEA) geomechanic single-phase flow within the SRV. The SRV is assumed to be a linear elastic medium with increased permeability and is isotropic. The semi-analytical method uses effective permeability to determine the distance between fractures, fracture aperture and total stress changes.

Since the 1980s, numerical and experimental studies to investigate the hydraulic fractures-natural fractures interactions have been conducted. Blanton (1982) reveals the tendency of hydraulic fracture crossing of preexisting fractures occurs only under high angle of approach and high stress difference. Warpinski and Teufel (1987) show that interaction between hydraulic fractures-preexisting fractures is influenced among other by reservoir stresses difference, distance between preexisting fractures, the pressure during the hydraulic fracturing and permeability. Shimizu et al. (2014) show that high approach angle and low permeability of the preexisting fractures result in limited hydraulic fracture-natural fractures interaction. Universal Distinct Element Code method has been employed by Pirayehgar and Dusseault (2014) to reveal that the branching occurs when the stress ratio is small. Kim and Schechter (2007) use a fracture network model, outcrop maps, computer tomography imaging, image logs and fracture data of cores to determine the fracture aperture. Yu and Aguilera (2012) solves a three-dimensional pressure diffusion equation in order to determine the lowering of pressure inside the SRV and to determine an effective hydraulic diffusivity coefficient for flow within the SRV by using an analytical model developed. Izadi and Elsworth (2014) utilizes the cubic law in determining the pressure drop within the SRV. There are analytical models to estimate aperture and extent of hydraulic fractures using the Young's modulus (Khristianovitch and Zheltov 1955; Geertsma and de Klerk 1969; Perkins and Kern 1961) and Poisson's ratio (Valko and Economides 2001). Bratton (2011) shows that the fracture complexity is affected by the anisotropy of the in situ stresses where less reservoir stress anisotropy results in a less distinct preference of direction of the hydraulic fracture network.

Several authors presented their work to determine the fracture aperture estimation during drilling. Sanfillippo et al. (1997) estimate the fracture aperture using the mud losses and the Poiseuille Law. Their methods can only accommodate the lowest mud losses volume equal to $20 \mathrm{~L}$ and only considers the natural fractures not the induced fractures. Lietard et al. (1996) determine the fracture aperture during drilling from the mud losses in fractures. Geertsma and de Klerk (1969) identify the hydraulic fracture width to be dependent on fracture length and height, shear modulus, injection rate and fluid viscosity. This method is limited as the fracture permeability is not considered in calculating the fracture aperture.

Based on the previous methods limitations, this work is integrating the finite element analysis results on the stimulated reservoir volume permeability, the injected volume, the Darcy law and the cubic law to identify the natural fracture and hydraulic fracture aperture, numbers and spacing.

\section{Hoadley field properties}

This study focuses on a tight gas reservoir located in the glauconitic formation. The formation of interest in the Hoadley Field Rimbey, Alberta, Canada, has thickness of about $43 \mathrm{~m}$ at a total vertical depth (TVD) of $1892 \mathrm{~m}$ (Rafiq et al. 2016). As the maximum stress is the maximum horizontal stress, the intermediate stress is the vertical stress and the minimum stress is the minimum horizontal stress; the fault regime of this field is strike slip. The maximum horizontal stress orientation is $48^{\circ} \mathrm{NE}$. The Medicine River coal 
Table 1 Initial formation properties

\begin{tabular}{lc}
\hline Properties & Value \\
\hline Ostracod formation dynamic Poisson ratio & 0.20 \\
Glauconitic formation dynamic Poisson ratio & 0.23 \\
Medicine River coal formation dynamic Poisson ratio & 0.28 \\
Mannville formation dynamic Poisson ratio & 0.24 \\
Injection depth pore pressure (MPa) & 9.19 \\
Pore pressure gradient (kPa/m) & 4.86 \\
Injection depth total vertical stress (MPa) & 45.6 \\
Total vertical stress gradient (kPa/m) & 24.1 \\
Initial permeability (mD) & 0.07 \\
Ostracod formation dynamic Young's modulus (GPa) & 45.0 \\
Glauconitic formation dynamic Young's modulus (GPa) & 45.0 \\
Medicine River coal formation Dynamic Young's modulus & 5.48 \\
(GPa) & \\
Mannville formation dynamic Young's modulus (GPa) & 35.4 \\
Injection depth total maximum horizontal stress (MPa) & 48.8 \\
Total maximum horizontal stress gradient (kPa/m) & 25.8 \\
Injection depth total minimum horizontal stress (MPa) & 22.1 \\
Total minimum horizontal stress gradient (kPa/m) & 11.7 \\
\hline
\end{tabular}

Table 2 Stimulated rock volume (SRV) dimensions

\begin{tabular}{llr}
\hline Case & Dimensions & Value \\
\hline Case 1 & length of SRV (m) & 174 \\
& width of SRV (m) & 60 \\
& height of SRV (m) & 60 \\
Case 2 & $90 \%$ of Case 1 length (m) & 157 \\
& $90 \%$ of Case 1 width (m) & 54 \\
& $90 \%$ of Case 1 height (m) & 54 \\
Case 3 & 63\% of Case 1 mesh sizes & \\
\hline
\end{tabular}

formation with $5 \mathrm{~m}$ thickness and the Mannville formation with $80 \mathrm{~m}$ thickness overlie the glauconitic formation. The Ostracod Formation with $87 \mathrm{~m}$ thickness underlies the glauconitic formation. The average permeability of the glauconitic formation is determined to be approximately $0.07 \mathrm{mD}$ from the study well's pressure buildup test and the nearby well's core test (Core Laboratories - Canada Ltd. 1985. Microseismic data (Eaton et al. 2014) documentation and inference of Mohr-Coulomb failure criterion predicted that the natural fracture has $30^{\circ}$ inclined angle relative to the maximum horizontal stress. Table 1 listed the properties.

The dynamic modulus properties are anticipated to have higher values than the static modulus presented by Jizba et al. (1990) as they are calculated from sonic logs. Microseismic monitoring data from Maulianda et al. (2014) are used to estimate the SRV dimensions and are listed in Table 2.

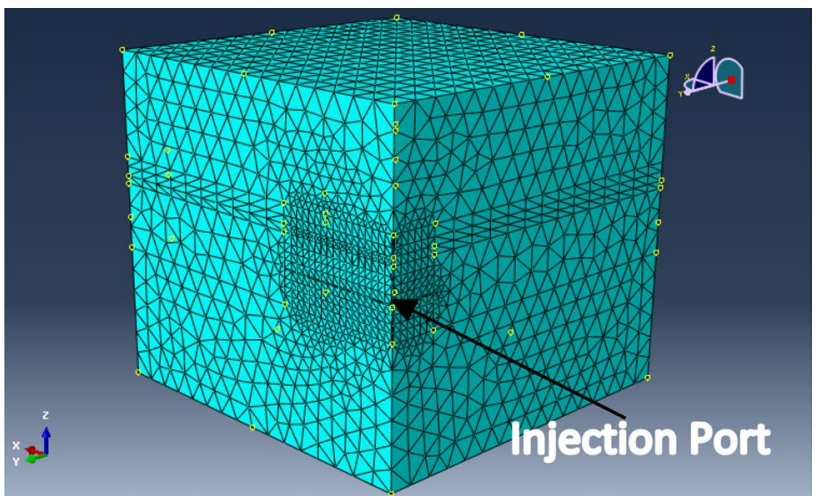

Fig. 1 Meshing of the finite elements for hydraulic fracturing (SRV) simulation

\section{Finite element model}

The software used to simulate the finite element model is called Abaqus, which is a software for finite element analysis. The modeling started by the creation of model geometry, in which the different formations are created without their properties by partitioning. Following that, the properties of each formation are created separately and it is assigned to the created geometry according to their respective sections. The initial and boundary conditions, which include the stresses, pore pressure and pumping step definition, are then applied onto the model. The model is then meshed following which the simulation can be run. The following sections describe in more details on the model created.

\section{Model geometry}

The model, displayed in Fig. 1, has the dimensions of: $240 \mathrm{~m}$ length ( $x$-axis) and $240 \mathrm{~m}$ width ( $y$-axis). It consists of four layers block. The total thickness of the model is $215 \mathrm{~m}$. This includes the $87 \mathrm{~m}$ Ostracod formation, the $43 \mathrm{~m}$ target glauconitic formation, the $5 \mathrm{~m}$ Medicine River coal layer and the $80 \mathrm{~m}$ Manville formation. The domain's bottom surface is located at $2000 \mathrm{~m}$ depth. From the microseismic data, it was identified that the SRV half-length is $87 \mathrm{~m}$ ( $x$-axis), while the width is $30 \mathrm{~m}$ ( $y$-axis). The total height of the SRV is $60 \mathrm{~m}$ ( $z$-axis). To take the stress field into consideration, the model size is made to be three times of the stimulated reservoir volume length.

To take into account SRV and non-SRV sections, the model is partitioned into seven sections. These seven sections are the Medicine River-non-SRV and SRV, Glauconitic-non-SRV and SRV, the Mannville-non-SRV and SRV, and the Ostracod-non-SRV. Dimensions of the SRV are determined from microseismic data as described in Maulianda et al. (2014). The model assumes that during the fluid injection, the SRV has a relatively high permeability.

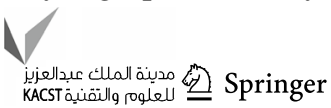


Each formation in the model has its own Poisson's ratio, permeability, Young's modulus, density, void ratio and host fluid specific weight, as listed in Table 1. The dynamic Young's modulus and dynamic Poisson's ratio are derived from sonic log data.

As the model is symmetrical across the $x=0$ plane and $y=0$ plane, quarter of the geometry is created with remaining three quarters represented by symmetrical planes. The model is discretized into a total of 9676 tetrahedral finite elements during the meshing. The meshing is made into two distinct sections. Firstly, the coarser section which make the formations, with mesh size equivalent to $16 \mathrm{~m}$. Secondly, the finer section which covers the SRV, which have a mesh size equivalent to $5 \mathrm{~m}$.

\section{Initial conditions and boundary conditions}

Parameters as follows are defined to specify the initial conditions: (a) the effective stresses, (b) the void ratio and (c) the pore pressure. Initial static equilibrium was achieved by applying the following loads on the domain: (a) The overburden stress of $43 \mathrm{MPa}$ which is applied on the top surface and was considered to be equal across the model top surface and (b) gravitational acceleration load of $9.8 \mathrm{~m} / \mathrm{s}^{2}$ applied on the whole in the negative z-direction.

In step two, a hydraulic fracture pumping stage is simulated. The injection with a total duration of $2250 \mathrm{~s}$ is divided into three steps. The durations of step one is $1 \mathrm{~s}$, step two is $10 \mathrm{~s}$ and step three is $2239 \mathrm{~s}$. Steps one and two are divided into ten equivalent steps. For step three, each time step is equivalent to $5 \mathrm{~s}$. Smaller time increments are applied in the earlier stage to study the consolidation when the loads are applied. In step two, injection velocity equivalent to flow rate of $5 \mathrm{~m}^{3} / \mathrm{min}$ is introduced to the surface representing the injection port. Boundary conditions representing the initial pore pressure are also introduced. By using a machine with specification of $2.2 \mathrm{GHz}$, 4-core and $16 \mathrm{~GB}$ of memory, an average of $1.5 \mathrm{~h}$ wall-clock time is required for the simulation.

\section{Results and discussion}

\section{Determination of the SRV effective permeability}

An iterative search was done by changing the SRV effective permeability until the simulated injected bottom-hole pressure matches the field average fracture propagation pressure. The average fracture propagation pressure from the field to be matched is equivalent to $27.6 \mathrm{MPa}$. The model only attempts to match the fracture propagation pressure which is taken at the final injection time as deformation and fracture initiation pressure are not taken into account. From

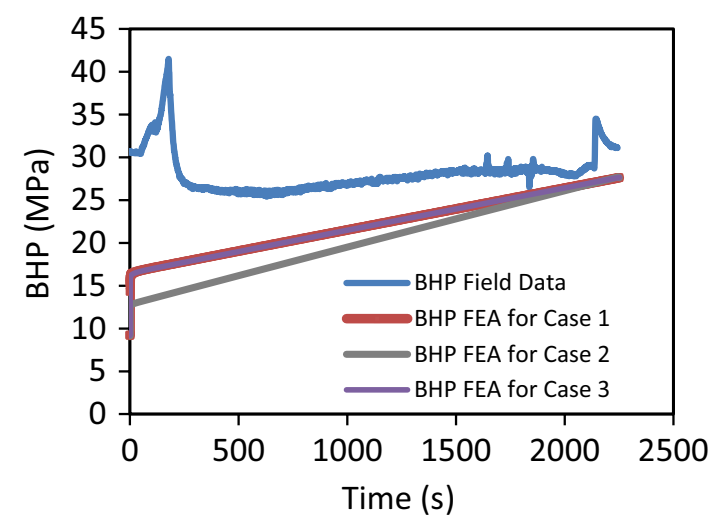

Fig. 2 Field bottom-hole injection pressure and FEA predicted results

the iterative search, the effective permeability of $23.4 \mathrm{mD}$ is found to give the best match to the bottom-hole pressure from the field data (permeability assumed to be isotropic) to match the SRV dimensions. The matched case is referred to as Case 1.

In determining the SRV dimensions effect on the effective permeability (arising from uncertainties of the microseismic data), a simulation was done in which each SRV dimension was reduced by $10 \%$ leading to an overall SRV volume reduction in $27 \%$. This case is referred to as Case 2 . The effective permeability for Case 2 required to match the field data is equal to $45.8 \mathrm{mD}$. Figure 2 also shows that in comparison with Case 1's bottom-hole injection pressure gradient of $4.9 \mathrm{kPa} / \mathrm{s}$, Case 2 has a higher gradient at $6.6 \mathrm{kPa} / \mathrm{s}$ at the early times $(0 \mathrm{~s})$ and late times $(2002 \mathrm{~s})$. However, the bottom-hole injection pressure gradient at the late time is similar for both Case 1 and Case 2.

A grid sensitivity was conducted: Case 3 is identical to Case 1 except the dimensions of the grid were reduced by $63 \%$. As shown in Fig. 2, the pore pressure profile changes by $0.17 \%$, whereas the deformation changes by a maximum value of $0.7 \%$ and the maximum change of the stress is less than $0.1 \%$. This demonstrates that the dimensions of the original mesh are sufficiently resolved.

The distribution of pore pressure within and around the SRV at various injection times for Case 1 are shown in Fig. 3. The pre-calculation distribution of pore pressure (initial condition) shown in Fig. 3a, b shows the initial distribution of pore pressure after applying the reservoir stresses. The distribution of pore pressure after $1 \mathrm{~s}, 551 \mathrm{~s}$ and $1101 \mathrm{~s}$ of fluid injection is displayed in Fig. 3c-e, respectively. After fluid injection for $1101 \mathrm{~s}$, the targeted bottom-hole pressure is almost reached. Lastly, Fig. $3 \mathrm{f}$ shows the maximum pore pressure at the injection port after $2250 \mathrm{~s}$; the pore pressure is $27.6 \mathrm{MPa}$, whereas at the SRV boundary, it is equal to $20.1 \mathrm{MPa}$. 


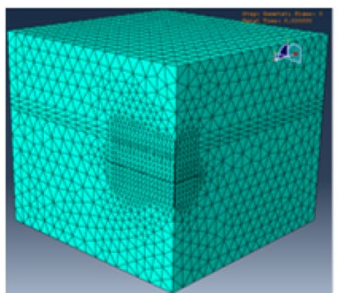

(a)

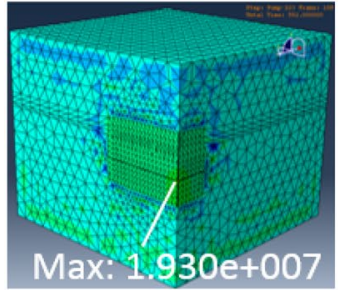

(d)

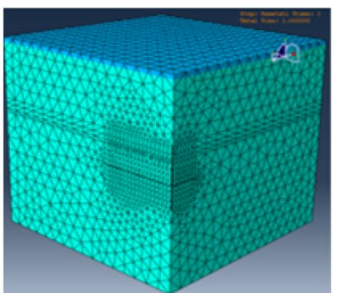

(b)

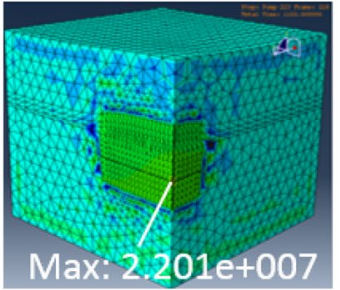

(e)

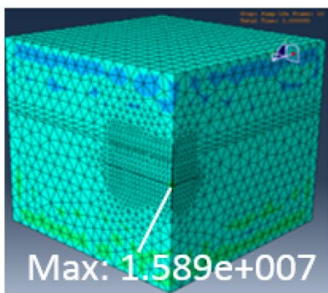

(c)

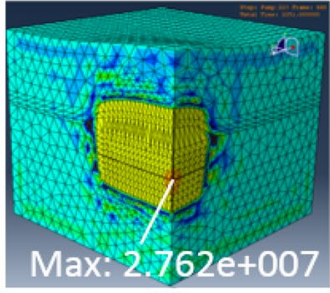

(f)

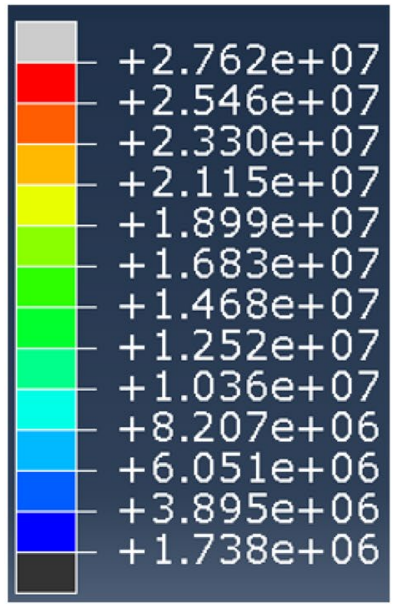

$+2.546 e+07$

$+2.330 \mathrm{e}+07$

$+2.115 e+07$

$+1.899 e+07$

$+1.683 e+07$

$+1.468 \mathrm{e}+07$

$+1.252 e+07$

$+1.036 \mathrm{e}+07$

$+8.207 e+06$

$+6.051 \mathrm{e}+06$

$+3.895 e+06$

$+1.738 \mathrm{e}+06$

Fig. 3 Case $1(k=23.4 \mathrm{mD})$ : a pore pressure $(\mathrm{Pa})$ following initial condition application, b pore pressure $(\mathrm{Pa})$ following reservoir stresses and boundary conditions application on the domain, $\mathbf{c} t=1 \mathrm{~s}, \mathbf{d} t=551 \mathrm{~s}, \mathbf{e} t=1101 \mathrm{~s}$ and $\mathbf{f}$ end of injection at $t=2250 \mathrm{~s}$

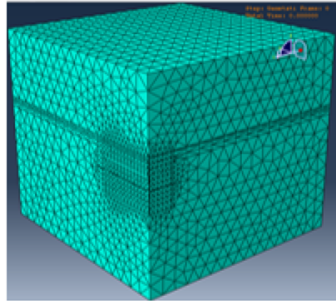

(a)

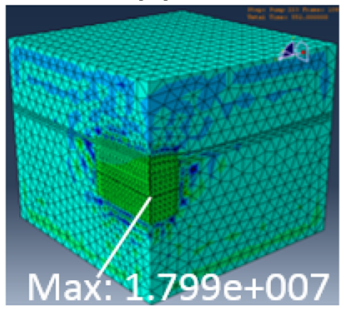

(d)

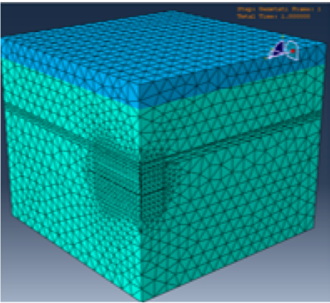

(b)

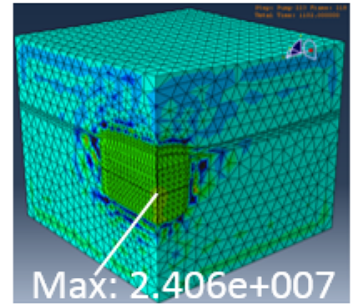

(e)

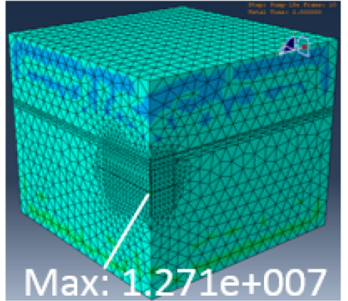

(c)

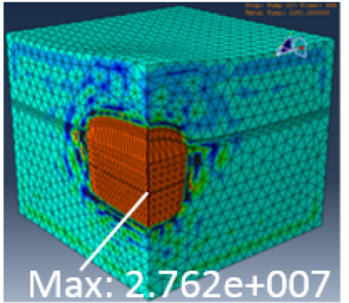

(f)

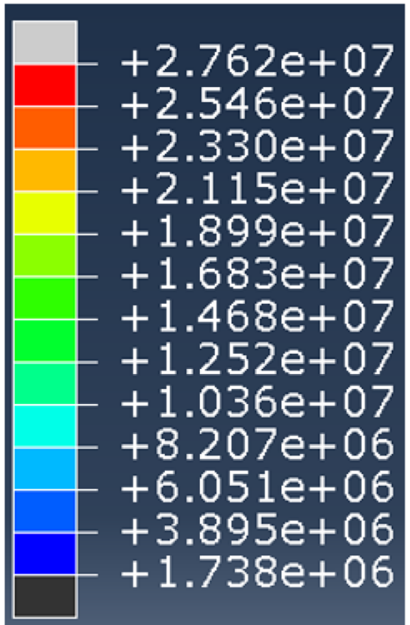

$+2.546 e+07$

$+2.330 \mathrm{e}+07$

$+2.115 \mathrm{e}+07$

$+1.899 \mathrm{e}+07$

$+1.683 e+07$

$+1.468 \mathrm{e}+07$

$+1.252 \mathrm{e}+07$

$+1.036 \mathrm{e}+07$

$+8.207 e+06$

$+6.051 e+06$

$+3.895 e+06$

$+1.738 e+06$

Fig. 4 Case $2(k=45.9 \mathrm{mD})$ : a pore pressure $(\mathrm{Pa})$ following initial condition application, $\mathbf{b}$ pore pressure $(\mathrm{Pa})$ following reservoir stresses and boundary conditions application on the domain, $\mathbf{c} t=1 \mathrm{~s}, \mathbf{d} t=551 \mathrm{~s}, \mathbf{e} t=1101 \mathrm{~s}$ and $\mathbf{f}$ end of injection at $t=2250 \mathrm{~s}$

The SRV's targeted bottom-hole pressure is obtained earlier in Case 2 as shown in Fig. 3f, 4f. Similar to Case 1, in Case 2, as the fluid is injected, the pressure rises within the $\mathrm{SRV}$, but the pressure is more uniform.

\section{Effect of SRV Young's modulus on its effective permeability}

To investigate the effect of SRV Young's modulus on effective permeability, parametric studies were conducted. The SRV Young's modulus was decreased to 90,80 and $70 \%$ of the original Young's modulus values. The sensitivity study for Case 1 shows that when reduction in 90, 80 and $70 \%$ of the SRV Young's modulus is made, the final bottomhole pressures are 27.0, 26.4 and $25.8 \mathrm{MPa}$, respectively. For Case 2, decreasing the SRV Young's modulus to 90, 80 and $70 \%$, the final bottom-hole pressures are 26.8, 26.0 and 25.1 MPa, respectively.

Additional parametric studies were also conducted to find the effective permeability which matches the final bottomhole pressure for the decreased Young's modulus values that give an injection pressure of 27.6 MPa. In Case 1, 70, 80 and $90 \%$ of the base Young's modulus resulted in matched effective permeability values of $18.4,20.0$ and $21.5 \mathrm{mD}$, 


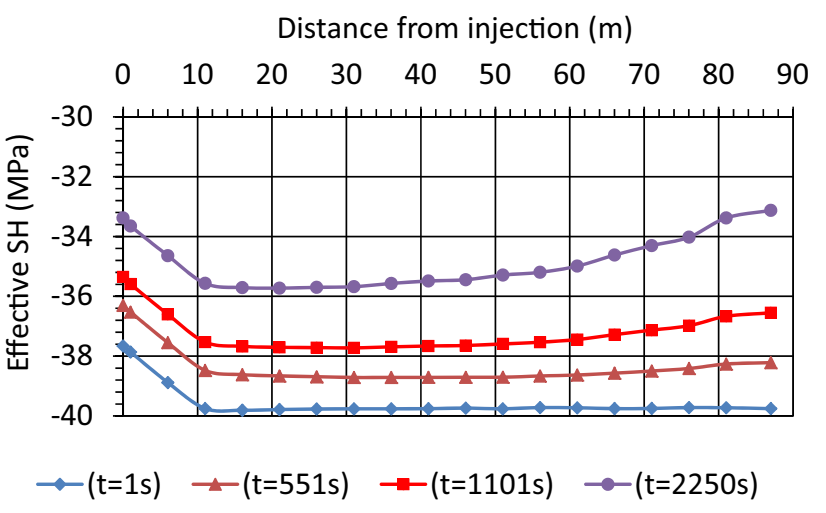

Fig. 5 Case $1(k=23.4 \mathrm{mD})$ : Effective maximum horizontal stress versus distance along the SRV length from the injection port at different injection times

respectively. For Case 2, 70, 80 and $90 \%$ of the base Young's modulus resulted in matched permeability values of 27.0 , 35.8 and $39.8 \mathrm{mD}$, respectively.

The parametric studies show that with a given injection rate and volume, the injection pressure decreases with increasing compressibility or decreasing Young's modulus. To maintain the same injection pressure, the SRV effective permeability has to be reduced. The reduction in effective permeability of the SRV could imply reduction in fracture aperture or spacing. Reduction in the SRV size leads to the effective permeability increase to maintain the same injectivity.

\section{Changes in Total Stresses in SRV due to Injection for Porous Medium}

The distributions of the effective maximum horizontal stresses, effective minimum horizontal stress and effective vertical stress in the SRV length, width and height are plotted in Figs. 5, 6 and 7 for Case 1 of the base Young's modulus. The pore pressure and effective stresses are generated by Abaqus throughout the model. Terzaghi (1925) effective stresses equation is used to calculate the total stresses. The results reveal that there is reduction in pore pressure from the injection port to a distance of about $10 \mathrm{~m}$ along the SRV, and the pressure drop is relatively small from that point on to the SRV boundary (Figs. 8a, 9a, 10a). The increases in the total maximum horizontal stress, the total minimum horizontal stress and the total vertical stress occur over the first $10 \mathrm{~m}$ from the injection port (Figs. 8b, 9b, 10b). These total stress increases are caused by the poro-elastic effect and fluid injection. Vermylen (2011) explained the poroelastic effect and fluid injection by stating that the total stress changes in reservoir due to hydraulic fracturing are attributed to three general causes: (a) tensile hydraulic fracture creation, (b) increased pore pressure in the reservoir due to

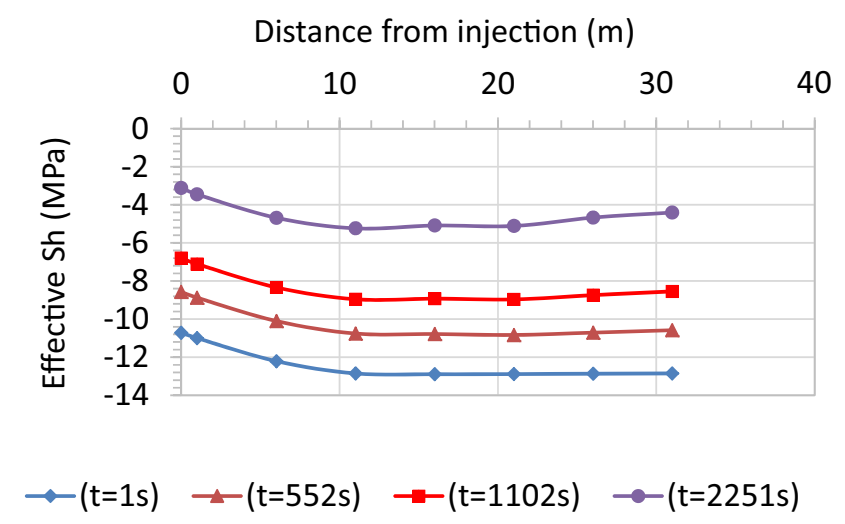

Fig. 6 Case $1(k=23.4 \mathrm{mD})$ : Effective minimum horizontal stress versus distance along SRV width from the injection port at different injection times

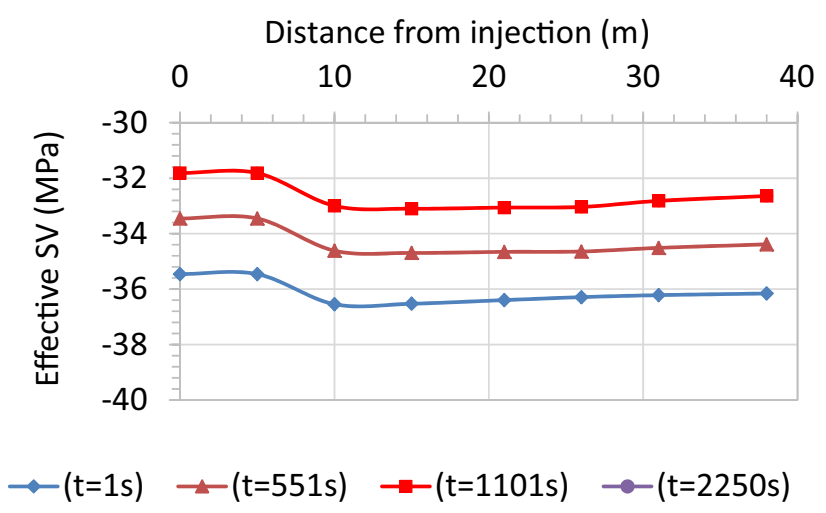

Fig. 7 Case $1(k=23.4 \mathrm{mD})$ : Effective vertical stress versus distance along SRV height from the injection port at different injection time

the effects of poro-elastic when there are fluid leakage from the hydraulic fracture and (c) propagation of the hydraulic fracture. From the injection port to a distance of $10 \mathrm{~m}$ from it, there are changes of the total stresses, and the changes are relatively small from that point to the SRV boundary as shown in Fig. 8b. The total maximum horizontal stress increased to $49 \mathrm{MPa}$ and $61 \mathrm{MPa}$ after the hydraulic fracture near the injection port. Over $1 \mathrm{~s}$ time period, no changes observed between $10 \mathrm{~m}$ from the injection port to the boundary of the SRV. However, at late injection time of 551, 1101 and $2250 \mathrm{~s}$, there are small increases in the total maximum horizontal stress between $10 \mathrm{~m}$ from the injection port to the boundary of the SRV, between $50 \mathrm{MPa}$ and $56.5 \mathrm{MPa}$ (Fig. 8b). In Abaqus, the convention is to use negative (-ve) number to describe compression stress, while positive (-ve) number is used for tensile stress.

The ratio of increase in total stress to increase in pore pressure is about 0.6. Similar trends in pore pressure and total stresses responses due to injection are observed in other two perpendicular directions (Figs. 9, 10). In this study, the 


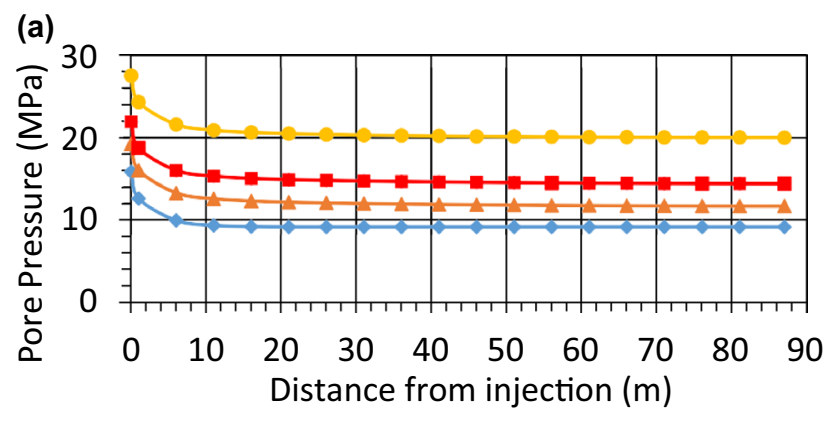

$$
\rightarrow-(\mathrm{t}=1 \mathrm{~s}) \rightarrow(\mathrm{t}=551 \mathrm{~s}) \rightarrow-(\mathrm{t}=1101 \mathrm{~s}) \rightarrow(\mathrm{t}=2250 \mathrm{~s})
$$

(b) $\quad \begin{array}{llllllllll}0 & 10 & 20 & 30 & 40 & 50 & 60 & 70 & 80 & 90\end{array}$

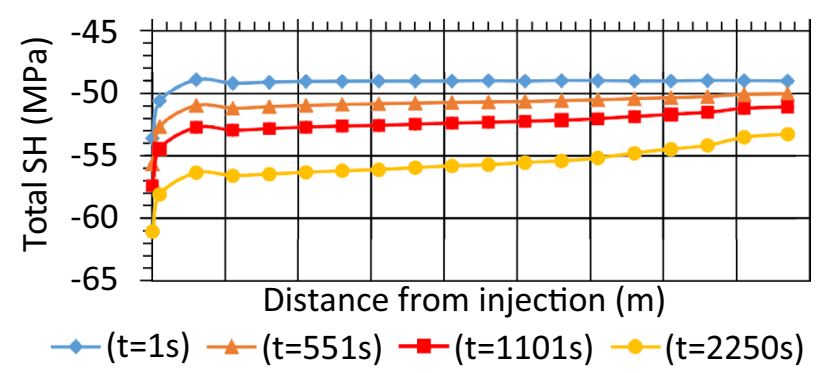

Fig. 8 Case $1(k=23.4 \mathrm{mD})$ : a Pore pressure versus distance and $\mathbf{b}$ total maximum horizontal stress versus distance along SRV length from the injection port at various injection times

(a)

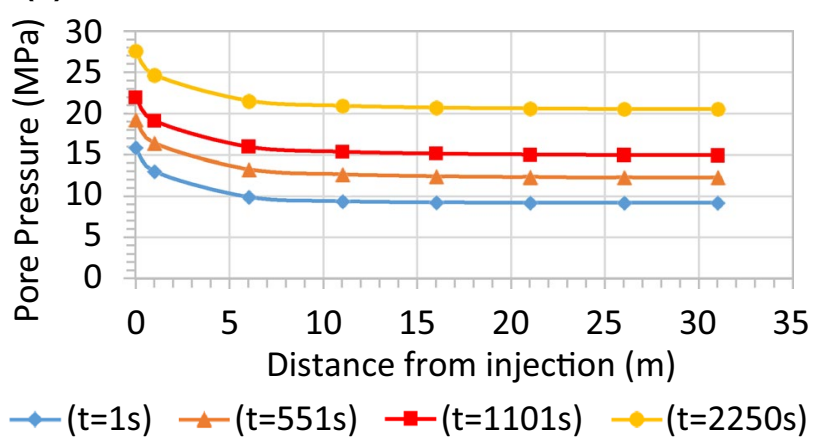

(b) $\begin{array}{llllllll}0 & 5 & 10 & 15 & 20 & 25 & 30 & 35\end{array}$

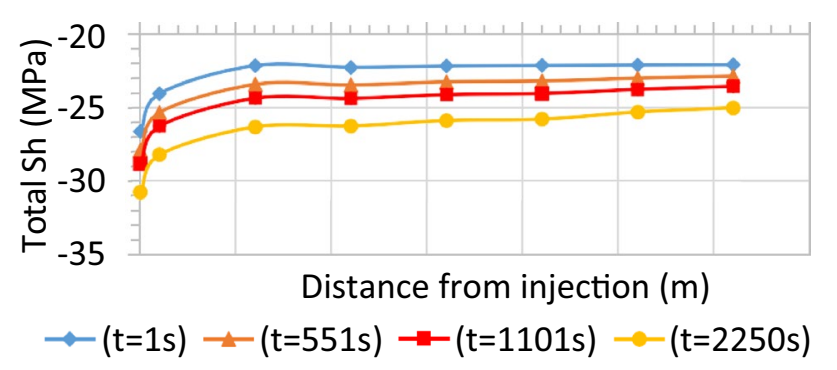

Fig. 9 Case $1(k=23.4 \mathrm{mD})$ : a Pore pressure versus distance and $\mathbf{b}$ total minimum horizontal stress versus distance along SRV length from the injection port at various injection times (a)

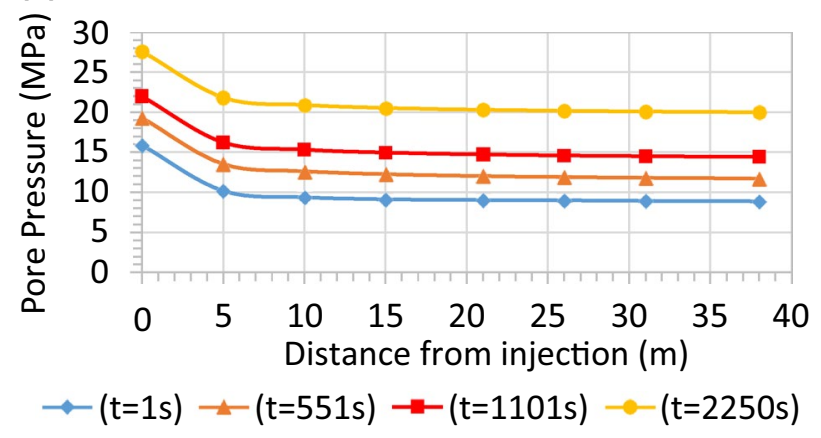

$\begin{array}{llllllllll}\text { (b) } & 0 & 5 & 10 & 15 & 20 & 25 & 30 & 35 & 40\end{array}$

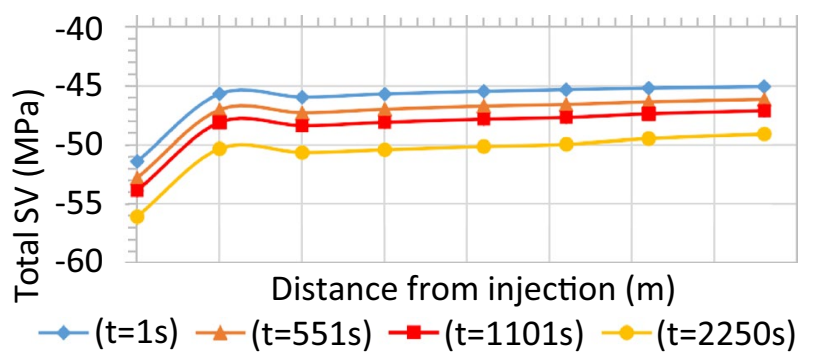

Fig. 10 Case $1(k=23.4 \mathrm{mD})$ : a Pore pressure versus distance and $\mathbf{b}$ total vertical stress versus distance along SRV height above injection ports at various injection times

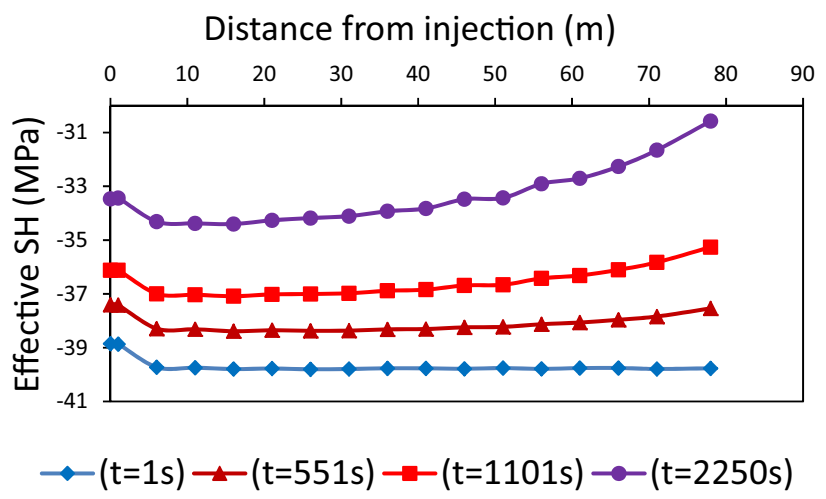

Fig. 11 Case $2(k=45.9 \mathrm{mD})$ : Effective maximum horizontal stress versus distance along SRV length from the injection port at different injection times

changes in the total stresses might be overestimated because of the assumption that the Biot's constant is equivalent to 1 . The total in situ stress changes due to pore pressure will be reduced for the glauconitic formation as the Biot's constant should be less than unity.

Profiles of the effective stresses for Case 2 are shown in Figs. 11, 12 and 13. The results are similar to those of 


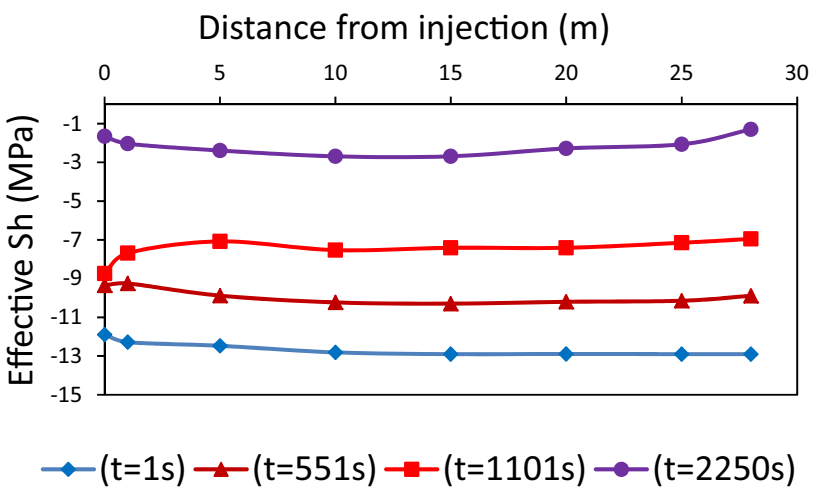

Fig. 12 Case $2(k=45.9 \mathrm{mD})$ : Effective minimum horizontal stress versus distance along SRV width from the injection port at different injection times

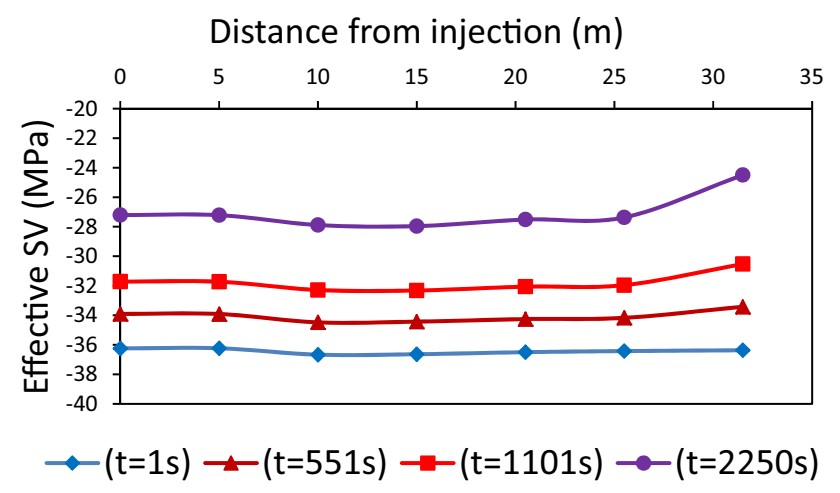

Fig. 13 Case $2(k=45.9 \mathrm{mD})$ : Effective vertical stress versus distance along SRV height from the injection port at different injection times

Fig. 14 Pore pressure versus distance using the cubic law equation for $\mathbf{a}$ Case 1 and $\mathbf{b}$ Case 2. $d=$ fracture aperture in $\mathrm{mm}$

\section{Determination of fracture aperture using Cubic Law}

The cubic equation is used to analytically calculate the pore pressure gradient along a planar fracture as shown in Eq. (1) (Brown 1987).

$Q L=-\frac{d^{3}}{12 \mu} \frac{\mathrm{d} P}{\mathrm{~d} x}$

where $L$ is the fracture width normal to fluid flow direction, $Q$ the flow rate, $P$ the fluid pressure, $d$ is the fracture aperture, $\mu$ the fluid viscosity and $x$ the distance.

Figure 14a shows the SRV changed fracture aperture and half-length for Case 1 and Fig. 14b for Case 2. The aperture is changed from 1.43 to $7 \mathrm{~mm}$ for Case 1 with maximum SRV half-length of $87 \mathrm{~m}$. The simulated pore pressure matched 20.1 MPa at the SRV boundary when the fracture aperture is $1.43 \mathrm{~mm}$. Figure 14b also shows that fracture aperture is changed for Case 2 from 1.78 to $7 \mathrm{~mm}$ with the maximum SRV half-length of $78 \mathrm{~m}$. The simulated pore pressure matched $23.8 \mathrm{MPa}$ at the SRV boundary when the fracture aperture is $1.78 \mathrm{~mm}$. The differences between the results of cubic law model and pore pressure of the finite element are that steady state flow is assumed for the cubic law model, whereas transient flow is assumed for the finite element modeling. In addition, geomechanics effect is not considered in the cubic equation.

\section{Fracture characteristics determination using semi-analytical approach}

Fracture characteristics are calculated from a developed semi-analytical approach in this section. Leak-off is

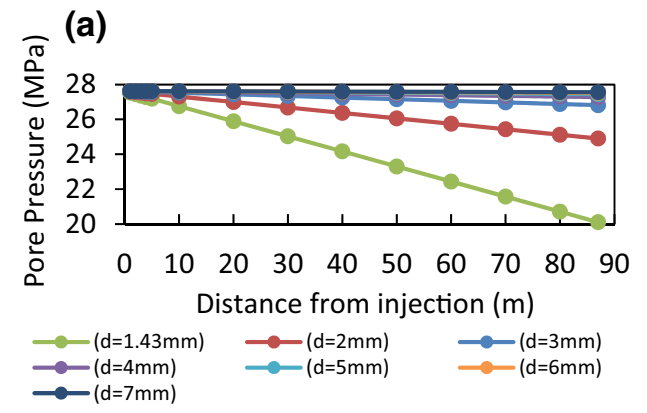

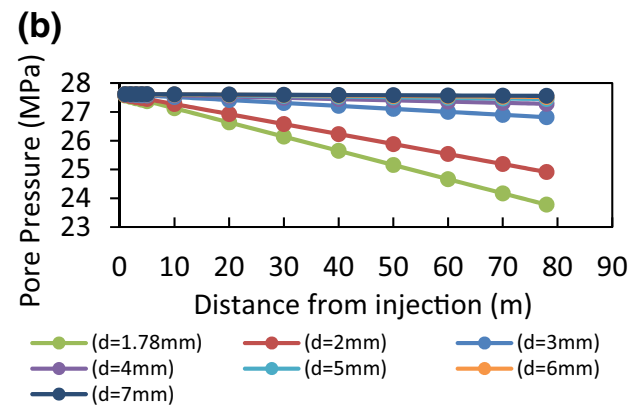

Case 1. The main difference between Cases 1 and 2 is that the pressure drops between the injection point and SRV boundary are 7.52 and $3.84 \mathrm{MPa}$, respectively. This is due to the elevated permeability used in Case 2. The horizontal stresses at the SRV boundaries at $2250 \mathrm{~s}$ are higher for Case 2 than for Case 1. The vertical stress is smaller for Case 2 by $0.8 \mathrm{MPa}$. This suggests that smaller SRV dimensions result in a higher stress increase (with all other properties are held constant). neglected by the semi-analytical. Major and minor fracture sets are assumed to create the fracture network within the SRV. The natural fractures are represented by the minor fracture. The hydraulic fractures (major fractures) are assumed to propagate through the SRV length, while the natural fractures (minor fractures) are inclined $30^{\circ}$ with respect to the maximum horizontal stress as shown in Fig. 15. Since the major fractures are assumed to connect the SRV boundaries, 
Fig. 15 Top view showing minor and major fractures

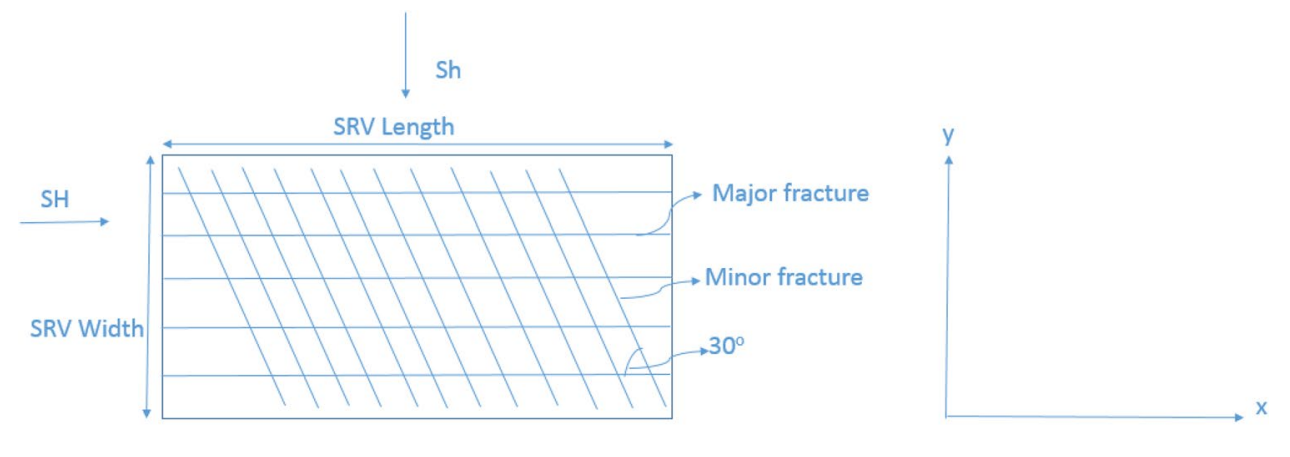

Fig. 16 Procedure to compute fracture aperture, number and spacing

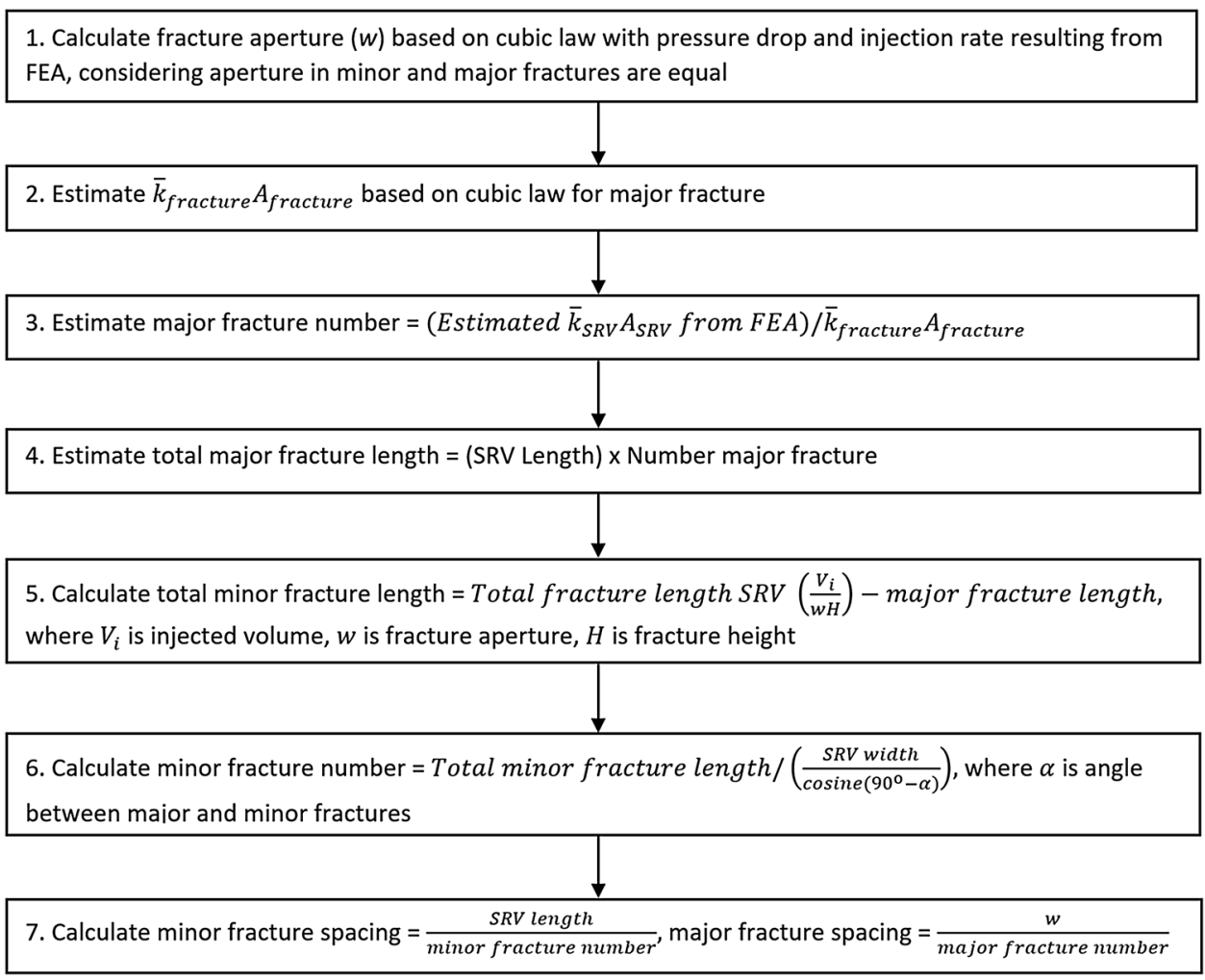

they contribute to both the SRV enhanced permeability and injected volume. On the other hand, as it is assumed that the minor fractures do not connect to the SRV boundaries and is a dead end, they assumed to contribute to the injected volume only. The approach assumes that major fractures (perpendicular to Sh) are created by the intersection of hydraulic fractures and natural fractures. Therefore, it is assumed that the hydraulic fractures and natural fractures are connected and the volume of the injected fracture fluid is contributed by it.

Calculating the major fracture number, minor fracture number, fracture spacing and fracture aperture requires two criteria. The two criteria used are the mass conservation criteria and equivalent flow characteristics criteria:

$\bar{k}_{\mathrm{SRV}} A_{\mathrm{SRV}}=\sum \bar{k}_{\text {fracture }} A_{\text {fracture }}$.
Injected volume $=$ Fracture volume .

In Eq. (2), $\bar{k}_{\mathrm{SRV}}$ is effective permeability obtained from FEA, while $A_{\mathrm{SRV}}$ is area of flow of the SRV, respectively. $\bar{k}_{\text {fracture }}$ is the cubic law-derived permeability, and $A_{\text {fracture }}$ is the flow area of each major fracture. An assumption of accumulation of all of the injected volume in both the major and minor fractures is used in Eq. (3) as shown in Fig. 15. The procedure used for the calculation of the fracture aperture, numbers and spacing is shown in Fig. 16.

The increase in fracture aperture for Case 1 from 1 to $2.1 \mathrm{~mm}$ results in a decrease in the major fractures numbers and loss of pressure along the SRV length (Fig. 17a). However, increasing fracture aperture from 1 to $1.43 \mathrm{~mm}$ results in the increase in the number of minor fracture; a further increase in fracture aperture induces a decrease in the 
Fig. 17 Relationship among fractures number, fracture aperture and fracture pressure gradient for a Case 1 and $\mathbf{b}$ Case 2. The apertures for the minor and major fractures are assumed to be equal (a)

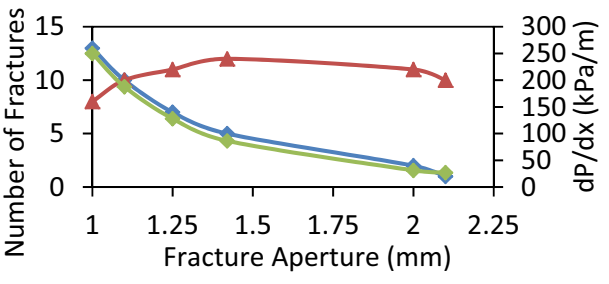

$\longrightarrow$ Number of Major Fracture $\longrightarrow$ Number of Minor Fracture

$\longrightarrow \mathrm{dP} / \mathrm{d} x$ (b)

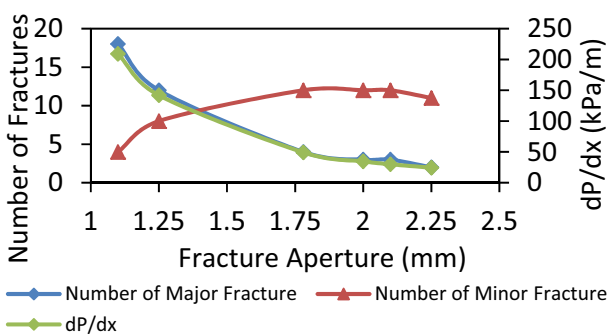

Table 3 Young's modulus and SRV effect on the major and minor fractures numbers

\begin{tabular}{lcllll}
\hline Aperture $(\mathrm{mm})$ & $\begin{array}{l}\text { Young's modu- } \\
\text { lus }(\%)\end{array}$ & SRV case & $\begin{array}{l}\text { Permeability } \\
(\mathrm{mD})\end{array}$ & $\begin{array}{l}\text { Major fractures } \\
\text { numbers }\end{array}$ & $\begin{array}{l}\text { Minor } \\
\text { fractures } \\
\text { numbers }\end{array}$ \\
\hline 1.43 & 100 & Case 1 & 23.4 & 5 & 12 \\
1.43 & 90 & Case 1 & 21.5 & 4 & 12 \\
1.43 & 80 & Case 1 & 20.0 & 4 & 13 \\
1.43 & 70 & Case 1 & 18.4 & 4 & 13 \\
1.78 & 100 & Case 2 & 45.9 & 4 & 12 \\
1.78 & 90 & Case 2 & 39.8 & 4 & 13 \\
1.78 & 80 & Case 2 & 35.8 & 3 & 13 \\
1.78 & 70 & Case 2 & 27.0 & 2 & 15 \\
\hline
\end{tabular}

number. This is due to the need of the total injected volume to match the total fracture volume of both the major and minor fractures. The increase in fracture aperture for Case 2 from 1.1 to $2.25 \mathrm{~mm}$ results in the decrease in the major fractures numbers and pressure drop along the SRV length while increasing the number of minor fractures until the fracture aperture is $2.1 \mathrm{~mm}$, and then, it decreases (Fig. 17b). Table 3 lists results for cases where the effective permeability of the SRV is reduced.

For a constant fracture aperture, smaller effective permeability results in lower number of the major fractures and greater the number of minor fractures. The response obtained for Case 2 is similar to those in Case 1. The fracture characteristics for Case 1 are as follows: 5 major fractures with spacing of $12 \mathrm{~m}$, and 12 minor fractures with spacing of $14.5 \mathrm{~m}$ and fracture aperture of $1.43 \mathrm{~mm}$. The fracture characteristics for Case 2 are as follows: 4 major fractures with spacing of $13.5 \mathrm{~m}, 12$ minor fractures with a spacing of $13 \mathrm{~m}$ and fracture aperture of $1.78 \mathrm{~mm}$.

\section{Conclusions}

The workflow developed in this study through the use of FEA and semi-analytical method in characterizing fractures within the stimulated rock volume (SRV) is novel. FEA provides the characterization of fracture in terms of pressure drop, enhanced permeability and in situ stress change which are caused by hydraulic fracturing. The major and minor fractures aperture, numbers and spacing in between are computed through the use of semi-analytical method using inputs of the simulated enhanced permeability and the injected fracture fluid volume. Young's modulus reduction leads to the increase the number of minor fractures for constant fracture apertures while decreases the effective permeability and the major fractures numbers. Decreasing the SRV dimensions by $10 \%$ of the original size resulted in the increase in the SRV effective permeability and decreases the pressure loss across the SRV. The hydraulic fractures effect the total in situ stress by increasing its values. Decreasing the size of the SRV dimensions leads to the increase in fracture apertures and the major fractures numbers while decreasing the minor fractures numbers to maintain the same decrease in pressure along the SRV length. For the case where the size of the SRV is calibrated to microseismic data from the field (Case 1), the analysis found the matching effective permeability to be $23.4 \mathrm{mD}$, fracture aperture to be $1.43 \mathrm{~mm}$, major fracture number to be 5 with spacing of $13.1 \mathrm{~m}$ and the minor fracture number to be 12 with spacing of $14.9 \mathrm{~m}$. For the case in which the SRV dimensions are reduced by $10 \%$ in each direction (Case 2), the matching effective permeability is $45.89 \mathrm{mD}$, the fracture aperture is $1.78 \mathrm{~mm}$, the major fracture number is 4 with the spacing of $13.1 \mathrm{~m}$ and the minor fracture number is 12 with the spacing of $12.9 \mathrm{~m}$. The variables tested in this study are applicable to improve the 
design of hydraulic fracturing in the Hoadley field or other formations and fields with similar geomechanical properties.

Acknowledgements The authors would like to acknowledge ConocoPhillips Canada for its support of the Hoadley Microseismic Experiment and associated field data. Special thanks go to NSERC for funding this research.

Open Access This article is distributed under the terms of the Creative Commons Attribution 4.0 International License (http://creativeco mmons.org/licenses/by/4.0/), which permits unrestricted use, distribution, and reproduction in any medium, provided you give appropriate credit to the original author(s) and the source, provide a link to the Creative Commons license, and indicate if changes were made.

\section{References}

Bahrami H, Rezae R, Hossain M (2012) Characterizing natural fractures productivity in tight gas. J Pet Explor Prod Technol 2(26): $107-115$

Blanton TL (1982) An experimental study of interaction between hydraulically induced and pre-existing fractures. In: SPE/DOE unconventional gas recovery symposium of the Society of Petroleum Engineers. Society of Petroleum Engineers

Bratton T (2011) Hydraulic fracture complexity and containment in unconventional reservoirs. In: ARMA workshop on rock mechanics/geomechanics. American Rock Mechanics Association

Brown SR (1987) Fluid flow through rock joints: the effect of surface roughness. J Geophys Res 92(82):1337-1347. https://doi. org/10.1029/JB092iB02p01337

Chen Z, Jeffrey RG, Zhang X, Kear J (2017) Finite-element simulation of a hydraulic fracture interacting with a natural fracture. Soc Pet Eng 15:12. https://doi.org/10.2118/176970-PA

Cipolla C, Wallace J (2014) Stimulated reservoir volume: a misapplied concept? In: SPE hydraulic fracturing technology conference. Society of Petroleum Engineers

Core Laboratories - Canada Ltd. (1985) Core analysis of Amoco Canada Petroleum Company Ltd - Amoco et al WROSES 11-2043-2W5 Glauconitic Formation in Westerose Southern Alberta

Eaton DW, Caffagni E, van der Baan M, Matthews L (2014) Passive seismic monitoring and integrated geomechanical analysis of a tight-sand reservoir during hydraulic-fracture treatment, flowback and production. In: Unconventional resources technology conference. Society of Petroleum Engineers

Gao Q, Ghassemi A (2018) Parallel finite element simulations of 3D hydraulic fracture propagation using a coupled hydro-mechanical interface element. American Rock Mechanics Association, Alexandria

Ge J, Ghassemi A (2011) Permeability enhancement in shale gas reservoirs after stimulation by hydraulic fracturing. In: the 45th US rock mechanics/geomechanics symposium. American Rock Mechanics Association

Geertsma J, de Klerk E (1969) A rapid method of predicting width and extent of hydraulically induced fractures. J Pet Technol 21:1571-1581

Guo T, Zhang S, Qu Z, Zhou T, Xiao Y, Gao J (2014) Experimental study of hydraulic fracturing for shale by stimulated reservoir volume. Fuel 128:373-380

Izadi G, Elsworth D (2014) Reservoir stimulation and induced seismicity: roles of fluid pressure and thermal transients on reactivated fractured networks. Geothermic 51:368-379. https://doi. org/10.1016/j.geothermics.2014.01.014
Jizba D, Mavko G, Nur M (1990) Static and dynamic moduli of tight gas sandstones. In: SEG conference. Society of Exploration Geophysicists

Johri M, Zoback MD (2013) The evolution of stimulated rock volume during hydraulic stimulation of shale gas formations. In: 2013 unconventional resources technology conference. Society of Petroleum Engineers

Khristianovitch SA, Zheltov YP (1955) Formation of vertical fractures by means of highly viscous fluids. In: 4th World Petroleum Congress

Kim TH, Schechter DS (2007) Estimation of fracture porosity of naturally fractured reservoirs with no matrix porosity using fractal discrete fracture networks. In: SPE annual technical conference and exhibition. Society of Petroleum Engineers

Lietard O, Guillot D, Hodder M (1996) Fracture width LWD and drilling mud/LCM selection guidelines in naturally fractures reservoirs. Society of Petroleum Engineers, Kuala Lumpur

Maulianda BT, Hareland G, Chen S (2014) Geomechanical consideration in stimulated reservoir volume dimension models prediction during multi-stage hydraulic fractures in horizontal wells-Glauconite tight formation in Hoadley field. In: the 48th US rock mechanics/geomechanics symposium. American Rock Mechanics Association

Mayerhofer MJ, Lolon E, Warpinski NR, Cipolla CL, Walser DW, Rightmire CM (2010) What is stimulated reservoir volume? SPE Prod Oper 25(01):89-98

Nassir M (2013) Geomechanical coupled modeling of shear fracturing in non-conventional reservoirs. Ph.D. dissertation, University of Calgary, Alberta, Canada. http://theses.ucalgary.ca/handl e/11023/394. Accessed 01.03.15

Oda M (1986) An equivalent continuum model for coupled stress and fluid flow analysis in jointed rock masses. Water Resource Res 22(13): 1845-1856

Perkins TK, Kern LR (1961) Widths of hydraulic fractures. J Pet Technol 13(9):937-949. https://doi.org/10.2118/89-PA

Pirayehgar A, Dusseault MB (2014) The stress ratio effect on hydraulic fracturing in the presence of natural fractures. In: the 48th US rock mechanics/geomechanics symposium. American Rock Mechanics Association

Rafiq A, Eaton DW, McDougall A, Pedersen PK (2016) Reservoir characterization using microseismic facies analysis integrated with surface seismic attributes. Interpretation 4(2):T167-T181

Rahman MK, Hossain MM, Rahman SS (2002) A shear-dilation based model for evaluation of hydraulically stimulated naturally fractured reservoirs. Int J Numer Anal Methods Geomech 26(5):469-497. https://doi.org/10.1002/nag.208

Sanfillippo F, Brignoli M, Santarelli FJ, Bezzola C (1997) Characterization of conductive fractures while drilling. Society of Petroleum Engineers, Kuala Lumpur

Shimizu H, Hiyama M, Ito T (2014) Flow-coupled DEM simulation for hydraulic fracturing in pre-fractured rock. In: the 48th US rock mechanics/geomechanics symposium. American Rock Mechanics Association

Terzaghi K (1925) Erdbaumechanik. Franz Deuticke

Valko P, Economides MJ (2001) Hydraulic fracture mechanics. Wiley, West Sussex

Vermylen JP (2011) Geomechanical studies of the Barnett shale, Texas, USA. Ph.D. dissertation. Stanford University, USA. https://www.google.com/search?q=\%5B33\%5D+Vermy len+JP.+Geomechanical+studies+of + the + Barnett + shale $\% 2 \mathrm{C}+$ Texas $\% 2 \mathrm{C}+\mathrm{USA} .+\mathrm{Ph} . \mathrm{D}+$ diss.+Stanford+University $\& r l z=1 \mathrm{C} 1 \mathrm{CHBF}$ enMY741MY741\&oq $=\% 5 \mathrm{~B} 33 \% 5 \mathrm{D}+$ Vermy len+JP.+Geomechanical+studies+of +the+Barnett+shale $\% 2 \mathrm{C}+$ Texas $\% 2 \mathrm{C}+\mathrm{USA} .+\mathrm{Ph} . \mathrm{D}+$ diss.+Stanford+University $\&$ aqs $=$ chrome $.69 \mathrm{i} 57.126 \mathrm{j} 0 \mathrm{j} 4 \&$ sourceid $=$ chrome $\& \mathrm{ie}=\mathrm{UTF}-8$. Accessed 01.03.15

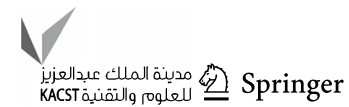


Wang H (2015) Numerical modelling of non-planar hydraulic fracture propagation in brittle and ductile rocks using XFEM with cohesive zone method. J Pet Sci Eng 135:127-140

Warpinski NR, Teufel LW (1987) Influence of geologic discontinuities on hydraulic fracture propagation. J Pet Technol 39:02. https://doi. org/10.2118/13224-PA

Yu G, Aguilera R (2012) 3D analytical modeling of hydraulic fracturing stimulated rock volume. In: SPE Latin American and
Caribbean petroleum engineering conference. Society of Petroleum Engineers

Publisher's Note Springer Nature remains neutral with regard to jurisdictional claims in published maps and institutional affiliations. 